ONE HUNDRED AND EIFTY-SECOND SCIENTIFIC MEETING

SIXTY-FIFTH SCOTTISH MEETING

CHEMISTRY BUILDING, MESTON WALK, OLD ABERDEEN

29 SEPTEMBER 1962

\title{
ASSESSMENT OF NUTRITIONAL STATUS IN MAN
}

\author{
Chairman : Dr Isabella Leitch, O.B.E., M.A., Formerly Director, Commonwealth \\ Bureau of Animal Nutrition, Bucksburn, Aberdeen
}

The assessment of nutritional status in man: Ghairman's opening remarks

By Isabella Leitch, Formerly Director, Commonwealth Bureau of Animal Nutrition, Bucksburn, Aberdeen

The assessment of nutritional status is an extremely complicated task. Nutritional status depends on, not only the food supply and the person, his age, state of development and activity, but also the environment, especially the environmental hygiene and exposure to infection. Those are linked in a complicated series of interactions.

It is not perhaps difficult to say whether a person is well or ill; it is much more difficult to define the cause of unwellness which may be lack of food or a component of food, or the presence of some component in excess, or overwork or worry, or infection. No-one has yet devised a method of measuring resistance to infection as conditioned by diet; it is recognized in the records of incidence and mortality.

Perhaps as a prelude to the statements to follow on nutritional status in man, I may summarize briefly the main conclusions from much of the earlier work on animal nutrition, laboratory animals and farm animals:

(I) The simplest criterion of adequate diet in growing experimental animals is weight increase, but weight increase is not synonymous with growth in body dimensions, and many misunderstandings have arisen from that confusion of ideas.

(2) In the adult, weight increase is neither good nor bad in itself. Gross obesity may be induced without apparent effect on health.

(3) A diet that gives a high growth rate may not give the best reproductive performance, but the difference will be one of minor adjustments, not of kind.

(4) Signs of deficiency are often non-specific. A rat with running fits may be suffering from lack of magnesium, or lack of pyridoxine, or excess of thiamine.

(5) Change in the composition of the blood is not the first result of distortion of diet, as we once thought, but often the last.

(6) Some poor diets appear to raise susceptibility to certain infections and infestations.

(7) It is possible by juggling with the quantity and proportions of some of the components of diet to curtail or extend the span of life in rats, as if a certain quantum of life were inherited which could be used fast or slowly. There is no evidence to show of how many animals the same may be true. 
From such observations standards of normality for diet and performance in growth, reproduction and duration of life have been set up. We look forward to hear from our speakers today how far the search for similar standards for man has progressed.

\section{The indices of nutritional change in Great Britain}

By W. T. C. Berry, Ministry of Health, Alexander Fleming House, Elephant and Castle, London, S.E.I, and

Dorothy F. Hollingsworth, Ministry of Agriculture, Fisheries and Food, London, S.W.I

\section{Nature of the indices}

We have applied the term 'indices of nutritional change' to the various statistical returns that may be used to reveal slow changes occurring through an entire country.

The indices that we find most useful are:

(I) Food Consumption Levels in the United Kingdom published annually in the Board of Trade Journal.

(2) The National Food Survey.

(3) The stillbirth and neonatal death rates.

(4) Records of growth.

(5) The rejection rate of women volunteering for blood donation for the first time.

(6) The death rate from arteriosclerotic heart disease.

The first (see, for example, Ministry of Agriculture, Fisheries and Food, I962) shows the amounts of foods available per person at the retail stage of distribution. It takes no account of distribution within the community, or of waste beyond the retail level. The second (e.g. Ministry of Agriculture, Fisheries and Food: National Food Survey Committee, I 962) is a record of food entering the household, and is thus one stage nearer the consumer. The results are regularly available in relation to income of the head of the household, family size and geographical region. The National Food Survey does not record sweets purchased, or soft or alcoholic drinks, or certain other items liable to be bought by members of the family other than the housewife. Both sets of data are evaluated in nutritional terms, and in the National Food Survey average 'intakes' are compared with average 'requirements' based on the recommended allowances of the British Medical Association (r950). Neither index provides information on intakes of individuals.

The significance of the stillbirth and neonatal death rates has been thoroughly discussed by Duncan, Baird \& Thomson (1952). The rates do not, of course, reflect nutritional changes only.

The growth rate of schoolchildren is a valuable index. Boyne, Aitken \& Leitch (1957) wrote 'we think that more use might be made of the measurements made as a routine in schools,' and in fact the Ministry of Health had anticipated their recommendation by arranging some years before with the Ministry of Education that data 